\title{
Hydraulic performance characteristics of impact sprinkler with a fixed water dispersion device
}

\author{
Zakaria Issaka ${ }^{1,2}$, Hong Li ${ }^{1 *}$, Yue Jiang ${ }^{1}$, Pan Tang ${ }^{1}$, Chao Chen ${ }^{1}$, Ransford Opoku Darko ${ }^{1,3}$ \\ (1. Research Center of Fluid Machinery Engineering \& Technology, Jiangsu University, Zhenjiang 212013, Jiangsu, China; \\ 2. Department of Agricultural Engineering, Tamale Technical University, Northern Region, Ghana; \\ 3. Department of Agricultural Engineering, University of Cape Coast, Central Region, Ghana)
}

\begin{abstract}
One way to adapt to the trend towards low-energy and to improve the hydraulic performance of the impact sprinkler under a low pressure condition is by means of a fixed water dispersion device. A fixed dispersion device disperses jet flow from the nozzle continuously. The shape of the tip, impact angle $(\theta)$, diameter $(D)$, and depth in the jet flow $(d)$ have significant influence on the hydraulic performance. In this study, the hydraulic performance characteristics of impact sprinkler as affected by the fixed water dispersion device were studied under indoor conditions. Radial water distributions from the sprinkler were obtained by experiments for the fixed water dispersion devices. MATLAB was used to transform the radial data into net data, and the uniformities were simulated in a square layout from 1 to 2 times the range $(R)$. The droplet size distributions from the fixed water dispersion devices were measured by a laser precipitation monitor (LPM). Results showed that the range increased with the increase of pressure, and the sprinkler with type $\mathrm{C}_{2}$ produced a rectangular-shaped water distribution pattern, while the range was maintained. A maximum uniformity of 71.56\%, 75.56\%, 77.23\%, 73.32\%, 78.88\% and 86.67\% was found for types $A_{1}, B_{1}, C_{1}, A_{2}, B_{2}$, and $C_{2}$, respectively under a pressure of $200 \mathrm{kPa}$. The uniformity from the sprinkler using type $C_{2}$ surpassed $80 \%$, while type $\mathrm{C}_{1}$ fell below. Droplet sizes from type $\mathrm{C}_{2}$ was best, and the mean droplet diameter decreased with the increase of pressure. Hence, type $\mathrm{C}_{2}$ can be selected for further optimization of the design features to improve the hydraulic performance of the impact sprinkler under low pressure conditions.
\end{abstract}

Keywords: fixed water dispersion device, impact sprinkler, range, water distribution, uniformity, droplet size DOI: $10.25165 /$ j.ijabe.20181106.4026

Citation: Issaka Z, Li H, Jiang Y, Tang P, Chen C, Darko R O. Hydraulic performance characteristics of impact sprinkler with a fixed water dispersion device. Int J Agric \& Biol Eng, 2018; 11(6): 104-112.

\section{Introduction}

Sprinkler irrigation is currently being promoted worldwide due to its numerous benefits of saving water and labor, and is adaptable to the needs of the farmers ${ }^{[1-3]}$. It prevents dry areas between furrows and deep percolation of water compared with surface irrigation methods ${ }^{[4-6]}$. Water saved in sprinkler irrigation varies from $40 \%-65 \%$, depending on the design, crop type, management practices and geographical location ${ }^{[2,7]}$. Several types of sprinklers exist, but the impact sprinkler is commonly used because it is relatively low-cost and more reliable. Due to its large range, the impact sprinkler is efficient for irrigating large areas. It operates by spraying pressurized water from the nozzle. As the jet flow from the nozzle and impact on the deflector, the head of the sprinkler is driven into a circular motion. The deflector arm is

\section{Receive date: 2017-12-08 Accepted date: 2018-08-01}

Biographies: Zakaria Issaka, PhD candidate, research interests: water-saving irrigation theory and technical innovation, Email: issakazak@gmail.com; Yue Jiang, Assistant Professor, research interests: irrigation theory and technical innovation, E-mail: jy261715267@126.com; Pan Tang, PhD, research interests: irrigation theory and technical innovation, Email: tangpan19@163.com; Chao Chen, Associate Research Fellow, research interests: design of water-saving irrigation equipment, Email: chch3605@ujs.edu.cn; Ransford Opoku Darko, $\mathrm{PhD}$, research interests: water-saving irrigation theory and technology, Email: chiefrodark@yahoo.com.

*Corresponding author: Hong Li, Professor, research interests: design of water-saving irrigation equipment. Research Center of Fluid Machinery Engineering and Technology, Jiangsu University, No.301 Xuefu Road, Zhenjiang 212013, China. Tel: +86-13952897655, Email: hli@ ujs.edu.cn. repeatedly pushed back into the jet flow by a spring-loaded arm each time it comes into contact with the jet flow. The deflector arm slightly affects the jet flow from the nozzle of the sprinkler ${ }^{[8]}$.

Uniformity is an important index for determining the hydraulic performance and irrigation quality of sprinklers. Considering the droplet trajectory and water distribution, only uniformity is a good indicator. It indicates the consistency in water distributions, which affects the productivity and efficiency in sprinkler irrigation systems $^{[9,10]}$. Under conditions of low uniformity, some areas are over irrigated, while the other areas are insufficiently irrigated, resulting in low crop yields and qualities ${ }^{[11]}$. Uniformity has a great influence on important aspects such as water use efficiency, leaching of nutrients and crop yields ${ }^{[12-14]}$. The factors that influence uniformity include the structure of the sprinkler, pressure head, spacing and layout, wind drift, air temperature, and relative humidity. A properly designed sprinkler irrigation system has the potential to produce high water application efficiency with a uniform water distribution ${ }^{[15,16]}$. Previous studies on the impact sprinkler mainly focused on the influence of factors such as nozzles, pressure, flow rate, riser, sprinkler spacing, and environmental factors $^{[17-19]}$.

Low pressure sprinkler irrigation is gaining momentum as the energy costs and the sustainability of pressurized irrigation need to be compromised. This is particularly important in the case of impact sprinklers for their pressure requirements are higher than for instance, pivot sprinklers. Impact sprinkler is unable to obtain sufficient jet break up when it is run under low pressure conditions, resulting in poor water distributions. Under high pressures, the jet breaks up sufficiently to produce a suitable distribution pattern. 
As the pressure is reduced, the distribution pattern becomes doughnut-shaped. Such conditions result in nonuniform water distributions, poor quality of irrigation and waste of water ${ }^{[11,20,21]}$. Hence, it is imperative to mechanically facilitate the breakup of the jet flow with a fixed water dispersion device to improve the water distributions under a low pressure. There are several ways to facilitate the breakup of the jet flow under low pressure condition. For example, an orifice nozzle, non-circular nozzles, vanes and fluidic devices can be mounted on the sprinkler ${ }^{[22,23]}$. Such dispersion devices are usually mounted outside the nozzle of the sprinkler. Some efforts were previously made to improve the water distribution with dispersion devices. Sprinkler manufacturers recently developed a noncircular nozzles which improved water distribution by dispersing the jet ${ }^{[35]}$. The drawback of this type of nozzle is that a large cross-section of the jet flow is usually deflected by the wind that is likely to decrease the range. Besides, the dispersed jet does not operate the impact arm efficiently, leading to some rotational problems. The use of multiple-nozzles on the sprinkler require smaller nozzles, which leads to plugging problems and decrease in the irrigation range. Flow control nozzles that uses a circular orifice which contracts with the increase of pressure were also used ${ }^{[24,25]}$. Similarly, vanes were also mounted on the upper part of the nozzle, which improved the range but resulted in poor water distributions. Few studies have been conducted on the use of water dispersion devices to improve water distribution under a low pressure. Fan developed and mounted a T-shaped rib parallel to the jet flow ${ }^{[26]}$. Kincaid developed and evaluated a new method of pattern modification using the impact $\operatorname{arm}^{[25]}$. A screw was mounted on the deflector arm, which intermittently dispersed the jet flow. This application is currently commercialized by NaanDan Jain Irrigation Limited ${ }^{[8]}$. $\mathrm{Li}$ studied the effect on the hydraulic performance of low pressure sprinkler using an intermittent water dispersion device ${ }^{[27]}$. These developments demonstrate the importance of water dispersion devices to the breakup and dispersion of water jet into droplets.

With respect to its axis of motion, a droplet is considered as symmetric with two forces acting on droplet in the air: (1) air resistance, which opposes the relative movement of the droplet and (2) gravity, which act vertically ${ }^{[28,29]}$. Air resistance decreases the magnitude of both velocity components. Gravity increases the magnitude of the vertical component when the droplet has a downward component, and to decrease it when the droplet has an upward component. Smaller droplets concentrate close to the sprinkler, while larger droplets settle towards the edge of the sprinkler range. Accurate knowledge of droplet size distributions is important to determine the difference in the droplet sizes resulting from a water dispersion device. First, smaller droplets are subject to wind drift that distorts the distribution pattern. Second, larger droplets possess greater kinetic energy which is transferred to the soil surface causing crusting and erosion ${ }^{[30,31]}$. This energy is directly related to drop sizes ${ }^{[32]}$. The rational behind the designs of the fixed water dispersion device is to facilitate the breakup of jet and maintain a large for impact sprinklers under low pressure conditions. The most important design parameters include; the shape of the tip, impact angle, diameter, and depth in the jet flow. In this study, we investigated the influence of the fixed water dispersion device on range, water distributions, uniformity, and droplet size distributions. This is necessary to select the correct fixed water dispersion device for further optimization to save irrigation water.

\section{Materials and methods}

\subsection{Structure of the fixed water dispersion devices}

The main structural parameters of a fixed water dispersion device in this study include; the diameter of dispersion device $(D)$, impact angle of the water stream $(\theta)$, the depth in jet flow $(d)$, and the shape of the tip (pointed or flat), as shown in Figure 1. Prototypes of the fixed water dispersion devices were self-designed and locally manufactured (Figure 2).
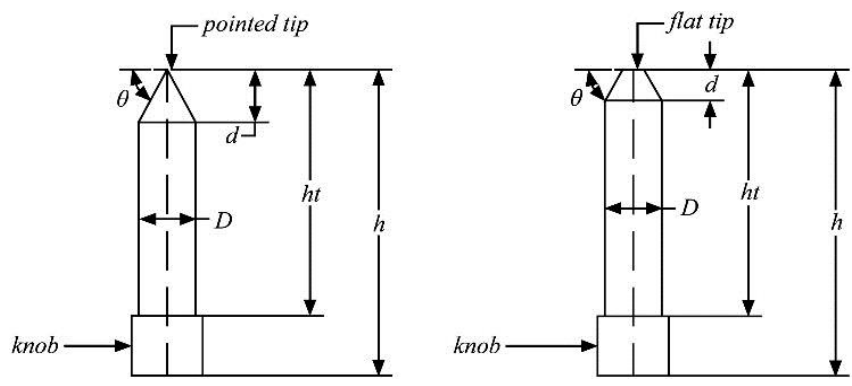

Note: $d$ : depth in jet flow; $a$ : impact angle; $h_{t}$ : length of thread mm; $D$ : diameter $\mathrm{mm} ; h$ : length of pin, mm.

Figure 1 Structure of different shapes of the fixed water dispersion devices

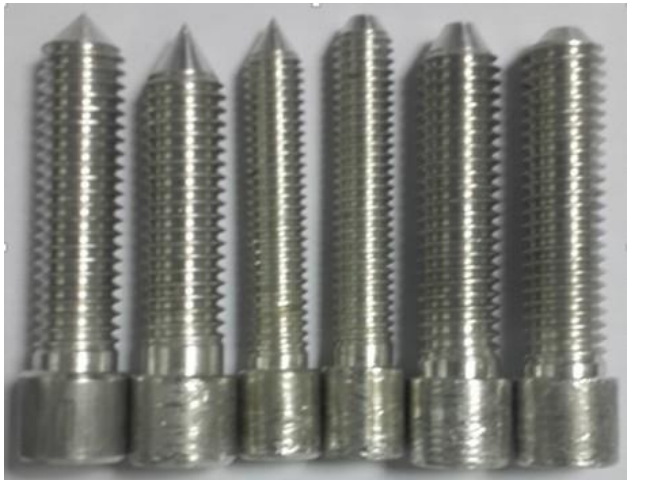

Figure 2 Prototypes of the fixed water dispersion devices

\subsection{Working principle of the fixed water dispersion device}

The Funny 1-inch impact sprinkler from Davide and Luigi Volpi Spa, Casalromano (CM), Italy was used for the experiment. The nozzle of the sprinkler was plastic, circular-shaped with an inlet and outlet diameters of $18 \mathrm{~mm}$ and $8 \mathrm{~mm}$, respectively. A hole was drilled in the holder or arm and threaded to accept the dispersion device. The arm was first screwed to the sprinkler, and then the fixed water dispersion device was inserted into a spring and screwed into the holder. The complete arrangement was then mounted on the sprinkler using a screw as shown in Figure 3. The spring provided vertical stability to the fixed water dispersion device during the impact from the jet. The tip of the dispersion device protruded into the jet flow, and as it is impacted by the jet, the flow was interrupted and caused a change in linear momentum and breakup. As a consequence, the inertia and angular momentum of the droplets were decreased, which made them to decelerate and fall near sprinkler. Otherwise, the jet travelled at a longer distance with respect to its axis of motion ${ }^{[12]}$.

Different shapes and structural parameters of the fixed water dispersion devices were considered in this study (Table 1). The shape of the tip, whether it is flat or pointed, was defined by the relation between $D, d$ and $\theta$, while the depth of the tip in the jet flow $(d)$ was also determined by the relation between $\theta, D$ and the shape of the tip.

Figure 5 shows the holder or arm for the fixed water dispersion device with a threaded hole to accept the dispersion device. 
Different holders were self-designed and locally manufactured based on the diameter of fixed water dispersion device (Figure 6).

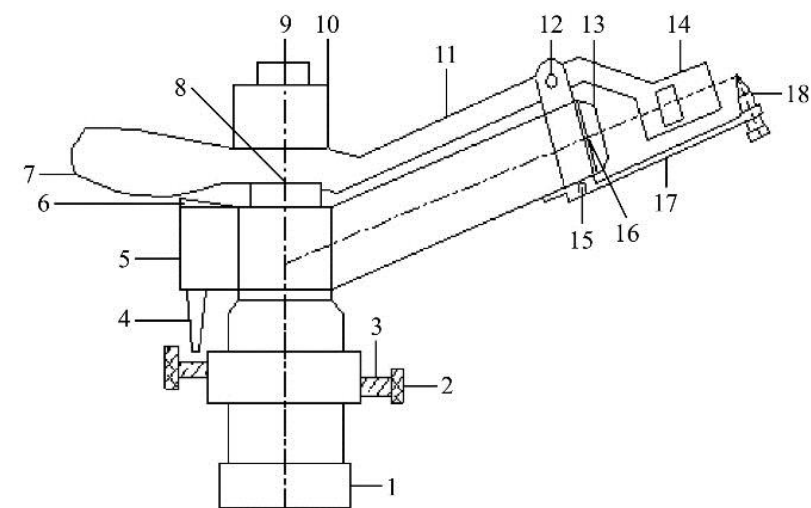

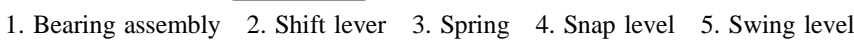
6. Stop shifter 7. Back arm 8. Bearing assemble 9. Inverted U-shaped mounting structure 10. Sprinkler head body 11. Impulse arm 12. Screw for arm 13. Nozzle 14. Deflector 15. Screw for device 16. Nozzle assembly 17. Arm for the dispersion device 18. The fixed water dispersion device

Figure 3 Structure of the impact sprinkler with a fixed water dispersion device

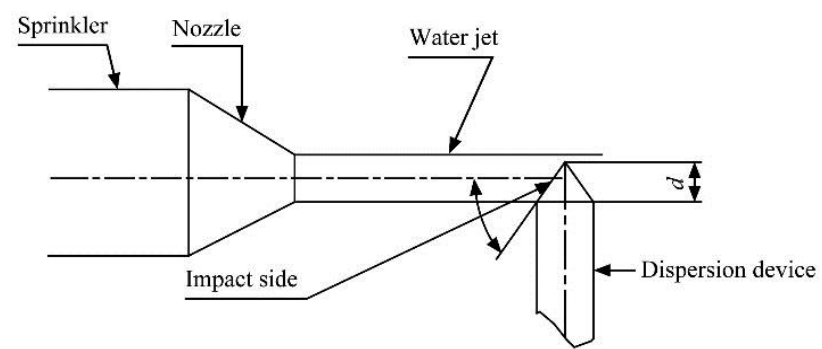

Figure 4 Schematic diagram of the fixed dispersion device impacted by jet flow: $a$ is the angle between the centerline of the nozzle and impact side of the dispersion device

Table 1 Structural parameters of different types of the fixed water dispersion devices

\begin{tabular}{ccccc}
\hline Type & $D / \mathrm{mm}$ & $\theta /\left(^{\circ}\right)$ & $d / \mathrm{mm}$ & Shape of the tip \\
\hline $\mathrm{A}_{1}$ & 6 & 45 & 1.5 & Flat \\
$\mathrm{B}_{1}$ & 6 & 60 & 2.5 & Flat \\
$\mathrm{C}_{1}$ & 8 & 60 & 4.0 & Flat \\
$\mathrm{A}_{2}$ & 6 & 45 & 3.0 & Pointed \\
$\mathrm{B}_{2}$ & 6 & 60 & 5.0 & Pointed \\
$\mathrm{C}_{2}$ & 8 & 45 & 4.0 & Pointed \\
\hline
\end{tabular}

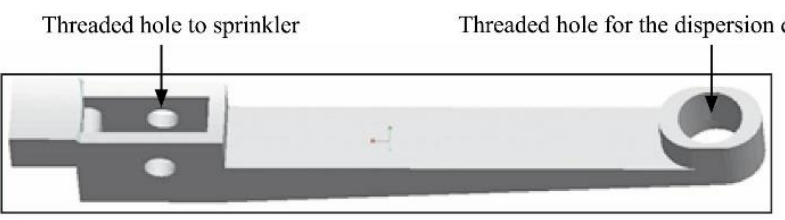

Figure 5 Structure of the arm for the fixed water dispersion device

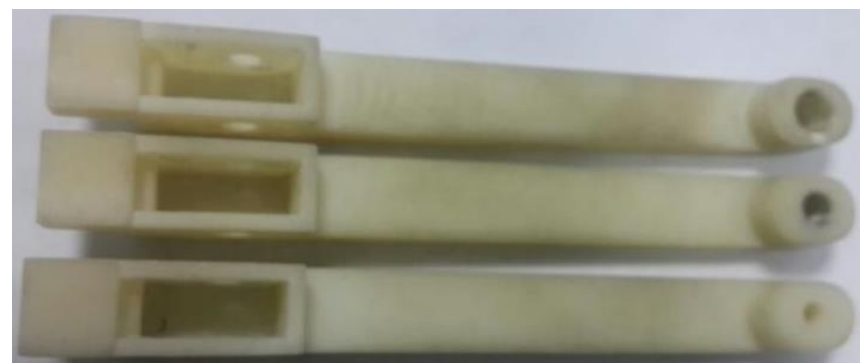

Figure 6 Prototypes of the holders/arms for the fixed water dispersion devices

\subsection{Experimental set-up}

The experiment was conducted in the sprinkler laboratory of the Research Center of Fluid Machinery Technology and Engineering, Jiangsu University in China. The laboratory has a circular shape with a diameter of $44 \mathrm{~m}$. The materials used for the experiment include; centrifugal pump, electromagnetic flow meter and piezometer, valve and the impact sprinkler (Figure 7). The sprinkler was installed at a height of $2 \mathrm{~m}$ from the ground level with a $23^{\circ}$ spraying angle. The sprinkler head was mounted on a $1.5 \mathrm{~m}$ high riser at an angle of $90^{\circ}$ to the horizontal from which the top of the catch cans was $0.9 \mathrm{~m}$ above the ground. Water was pumped from the reservoir through a main pipe and sprayed out from the nozzle. The pressure was measured at the base of the sprinkler using a pressure gauge with an accuracy of $0.4 \%$.

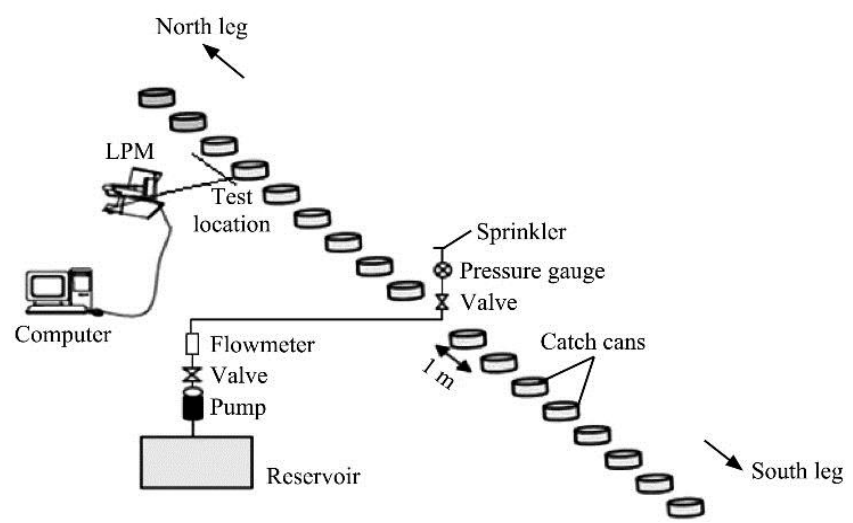

Figure 7 Schematic diagram of the experimental set-up for radial water distribution and Laser precipitation monitor (LPM) system

The system was pre-tested and adjusted where necessary to ensure the correct depth of the fixed water dispersion device was set into the jet flow. In order to standardize the laboratory conditions, the sprinkler was run for $20 \mathrm{~min}$ before performing the actual experiments. The array method was used to experimentally determine the sprinkler ranges. Rain gauges were arranged into two arrays (North and South legs), with $1 \mathrm{~m}$ spacing between them. The ranges were measured based on ASABE requirements, which establishes that the sprinkler range should be measured from the central sprinkler tested to the collector which received a precipitation intensity of at least $0.3 \mathrm{~mm} / \mathrm{h}$ (the point with irrigation intensity of $0.15 \mathrm{~mm} / \mathrm{h}$ when the spray flow is below $\left.0.25 \mathrm{~m}^{3} / \mathrm{h}\right)^{[33]}$. Tests were firstly carried out with no water dispersion device installed on the sprinkler. Each experiment period lasted for 1 hour, which the dates and times of irrigation were recorded, as well as the pressure, and the flow rate. The data for each dispersion device tested was based on three repetitions, and the average of radial distribution profile was taken as final values. During the experiment, all the parameters were maintained except for the fixed water dispersion devices and pressure. The pressure was varied from $100-400 \mathrm{kPa}$.

\subsection{Calculation of combined uniformity (CU)}

Square layout is widely used in irrigation management because it is more convenient for pipeline design and practical engineering ${ }^{[34]}$. Square layout was used for simulation of uniformity for different types of the fixed water dispersion device under different spacing coefficients (Figure 8). Spacing coefficient describes the overlap device distance of two sprinklers, which is equal to two times of the range $(R)$. Many irrigators in windy areas use $2 R$ or greater to provide enough overlap and achieve the desired uniformity. In this study, four sprinklers were mathematically overlapped at a maximum spacing 
coefficient of $2 R$, and the combined $C U \mathrm{~s}$ determined. The spacing coefficient describes the overlapping distance of two adjacent sprinklers for two different layout forms, and the spacing coefficient was equal to the times of the sprinkler range. The uniformity from the overlapped sprinkler gave the combined or simulated uniformity.

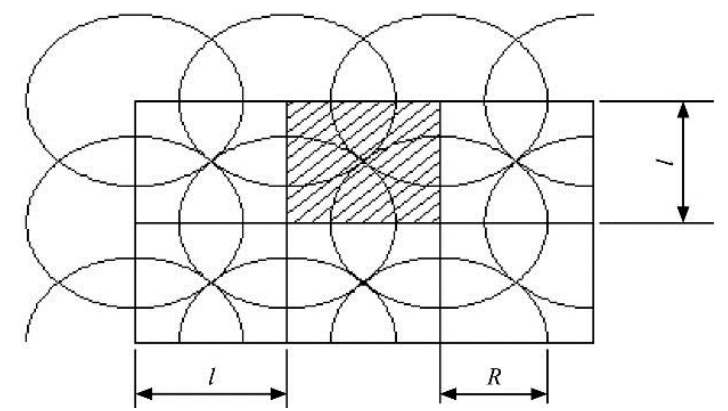

Figure 8 Schematic diagram of sprinkler under square layout

Matrix Laboratory (MATLAB) program was used to compute the combined $C U$ values according to the radial water distribution $^{[35,36]}$. Radial data of water distributions from the fixed water dispersion devices were modified into net data. The final calculated average radial water distribution data was the same in all directions for the types $\mathrm{A}_{1}, \mathrm{~B}_{1}, \mathrm{C}_{1}, \mathrm{~A}_{2}, \mathrm{~B}_{2}$ and $\mathrm{C}_{2}$. The available data points were distributed in a manner similar to a spider web. Grid data points were used to calculate the combined $C U$. The depth of the net point depends on the distance away from the sprinkler. The water depths of every interpolating point, assumed to be a continuous variable value, were calculated by using a mathematical model of interpolating cubic splines $^{[22,23]}$.

The model for converting radial data into the net data insert function was established as follows: Point $A$ was the net point between two adjacent radial rays, and $\left(x_{A}, y_{A}\right)$ was its coordinate. $P_{1}, P_{2}, P_{3}$, and $P_{4}$ are the four nearest points to point, $A$ on the two adjacent radial rays, and $\left(\rho_{1}, \theta_{1}\right),\left(\rho_{2}, \theta_{2}\right),\left(\rho_{3}, \theta_{3}\right)$, and $\left(\rho_{4}, \theta_{4}\right)$ were their coordinates. Hence, their positions were; $x_{i}=\rho_{i} \cos \theta_{i}(i=1$, $2,3,4)$ and $y_{i}=\rho_{i} \sin \theta_{i}(i=1,2,3,4)$. Their water depths were; $h_{1}, h_{2}, h_{3}$, and $h_{4}$, and the distances away from point $A$ are $r_{1}, r_{2}, r_{3}$, and $r_{4}$ respectively. Thus,

$$
r_{1}=\sqrt{\left(x_{1}+x_{A}\right)^{2}+\left(y_{1}-y_{A}\right)^{2}} \quad(i=1,2,3,4)
$$

The water depth of every net point was calculated by using the Equation (2) below:

$$
h_{A}=C_{1} h_{1}+C_{2} h_{2}+C_{3} h_{3}+C_{4} h_{4}
$$

where, $C_{1}=\left(r_{1} r_{2} r_{3}\right)^{2} / R, C_{2}=\left(r_{1} r_{3} r_{4}\right)^{2} / R, C_{3}=\left(r_{2} r_{3} r_{4}\right)^{2} / R, C_{4}=\left(r_{1} r_{3} r_{4}\right)^{2} / R$ and $R=\left(r_{1} r_{2} r_{3}\right)^{2}+\left(r_{1} r_{3} r_{4}\right)^{2}+\left(r_{1} r_{3} r_{4}\right)^{2}+\left(r_{2} r_{3} r_{4}\right)^{2}$.

Uniformity coefficient reflects the degree of water distributions, and its significance on crops growth is a measurement of the quality of sprinkler irrigation. Christiansen's uniformity coefficient was used in this study as an evaluation index ${ }^{[37]}$. The equation is given by

$$
C U=100\left[1-\frac{\sum\left|x_{i}-x_{m}\right|}{\sum x_{i}}\right]
$$

where, $C U$ is Christiansen's uniformity coefficient, \%; $x_{i}$ is the measured depth of water in equally spaced catch cans on a grid, $\mathrm{m}$; $x_{m}$ is the mean depth of water of the catch in all cans, $\mathrm{m}$.

\subsection{LPM experimental system}

The LPM from Thies Clima in Germany was used to measure the droplet diameters from the dispersion devices. The LPM consists of two main components: (1) an imaging system composed of photodiode detector, laser transmitter, a storage circuit, and (2) an analysis display system which is composed of Laser Line Narrowing Module (LNM) view software which displayed the data generated. The LPM can accumulate the measured droplet volumes and calculate the rainfall intensity, and the droplet spectra of LPM can be drawn, containing the droplet size ranges, droplet speed range, and the corresponding particle numbers. The data collected per minute was transferred into an EXCEL file. the test area is $46 \mathrm{~cm}^{2}(23.0 \mathrm{~cm} \times 2.0 \mathrm{~cm})$; the measurement range of particle diameter is $0.16-8.00 \mathrm{~mm}$; the measurement range of rainfall intensity is $0.005-250.000 \mathrm{~mm} / \mathrm{h}^{[38]}$.

\subsection{Calculation of droplet size distributions}

Jet flow from the nozzle break up by the air entrainment, forming numerous different diameter droplets, which falls within the spray area. The average droplet diameter represents the drop size at different positions due to the changing droplet diameter in a comparatively larger range. The average droplet diameter was calculated using the realistic Weighted Average Method (WAM). $W A M$ is the ratio of the corresponding weight of droplet diameters by different standard sieve meshes to the total weight of droplets at the sample location ${ }^{[38]}$ as shown in the equations below:

$$
\begin{gathered}
\bar{d}=\frac{\sum_{i=1}^{n} W_{i} d_{i}}{\sum_{i=1}^{n} W_{i}} \\
W_{i}=m_{i} \frac{\pi}{6} d_{i}^{3} \gamma_{i} \\
d_{V}=\frac{\sum_{n-1}^{n} d_{i}^{4}}{\sum_{n=1}^{n} d_{i}^{3}} \\
S D_{D}=\sqrt{\frac{1}{n-1} \sum_{i=1}^{n}\left(d_{i}-\bar{d}\right)^{2}} \\
C V_{D}=\frac{S D_{D}}{\bar{d}} \times 100 \%
\end{gathered}
$$

where, $\bar{d}$ is the average size of droplets at sampling locations, $\mathrm{mm} ; d_{i}$ is drop diameter, $\mathrm{mm} ; W_{i}$ refers to the weight of water for droplet with diameter $d_{i} ; \gamma_{w}$ is the bulk density of water, $\mathrm{N} / \mathrm{m}^{3} ; m_{i}$ is the number of droplet with diameter, $d$; and $n$ corresponds to the types of droplet diameters. The arithmetic mean, standard deviation $\left(S D_{D}\right)$, and coefficient of variation $\left(C V_{D}\right)$ were also used for droplet diameters.

\section{Results and discussion}

\subsection{Sprinkler ranges}

The pressure, flow rate, and water dispersion devices are factors that significantly influence sprinkler range of jet flow from a specific nozzle and sprinkler models. Measurements from the experiment were repeated three times and the averages were taken as final results. The relationship between the sprinkler ranges and pressures for different types of the fixed water dispersion devices are shown in Table 2. Without the fixed water dispersion device $\left(\mathrm{N}_{\mathrm{D}}\right)$, the water jet traveled longer according to Newton's third law of motion, resulting in a larger sprinkler range ${ }^{[27]}$. Generally, using a water dispersion device interrupted jet flow from the nozzle, caused it to disperse with a slight reduction in the sprinkler range. And different types of the fixed water dispersion devices gave a slight difference in the sprinkler ranges under the same pressure. However, the differences in sprinkler ranges were quite large for the fixed water dispersion devices with a pointed tip, while that with a flat tip had a considerably smaller sprinkler ranges. 
Table 2 Ranges for the fixed water dispersion devices under different pressures

\begin{tabular}{cccccccc}
\hline & \multicolumn{7}{c}{ Pressure/kPa } \\
\cline { 2 - 8 } Type & 100 & 150 & 200 & 250 & 300 & 350 & 400 \\
\hline $\mathrm{A}_{1}$ & 12.1 & 12.9 & 13.7 & 14.8 & 15.2 & 15.8 & 16.7 \\
$\mathrm{~B}_{1}$ & 11.7 & 12.5 & 13.6 & 14.3 & 14.8 & 15.4 & 16.2 \\
$\mathrm{C}_{1}$ & 11.1 & 11.7 & 12.2 & 13.9 & 14.1 & 15.1 & 15.9 \\
$\mathrm{~A}_{2}$ & 12.4 & 13.7 & 14.5 & 15.2 & 15.7 & 16.1 & 17.1 \\
$\mathrm{~B}_{2}$ & 11.9 & 13.1 & 14.1 & 14.7 & 15.2 & 15.7 & 16.8 \\
$\mathrm{C}_{2}$ & 11.6 & 12.8 & 13.4 & 14.2 & 14.8 & 15.3 & 16.3 \\
$\mathrm{~N}_{\mathrm{D}}$ & 12.7 & 13.1 & 14.4 & 15.4 & 16.7 & 17.8 & 19.1 \\
\hline
\end{tabular}

When using a pressure of $200 \mathrm{kPa}$, the sprinkler range from $\mathrm{A}_{2}$ was largest with a value of $14.5 \mathrm{~m}$. This was possibly due to a smaller surface area for the interruption of jet flow, leaving it undisturbed for a sufficient irrigation within the period to maintain a large range. Type $C_{1}$ had a larger surface area in the jet, the sprinkler range was reduced to $12.2 \mathrm{~m}$. The coefficient of variation $(C V)$ for type $\mathrm{C}_{1}$ had a leas value of $4.6 \%$, and type $\mathrm{C}_{2}$ was $1.8 \%$. With an increase in pressure, the $C V \mathrm{~s}$ were $3.7 \%$ and $1.6 \%$ for $\mathrm{C}_{1}$ and $\mathrm{C}_{2}$, respectively. A significant difference $(p<0.05)$ was found between $\mathrm{C}_{1}$ and $\mathrm{C}_{2}$, while a non-significant difference $(p>0.05)$ occurred for type $\mathrm{C}_{2}$ between the pressure ranges of 200 and $300 \mathrm{kPa}$. The depth of a fixed water dispersion device in the jet flow was decided by the impact angle, diameter and shape of the tip. With respect to type $\mathrm{C}_{2}$, it was possible to modify the water distribution pattern to produce a rectangular-shaped pattern while maintaining a large sprinkler range at the same time.

\subsection{Radial water distributions}

A uniform water distribution has a high application rate near the sprinkler and the profile decreases at a uniform rate as the range increases. The shape of the water distribution pattern is mainly determined by the sprinkler model and its internal design, discharge angle and jet breakup mechanism ${ }^{[15]}$. Water application rates from the fixed dispersion devices were different for each experiment with respect to the pressure ranges. The water distributions were mostly concentrated around sprinkler and at a distance far away from the sprinkler from a pressure of 100$150 \mathrm{kPa}$, which was possibly due to unsatisfactory pressure. Research on the doughnut-shaped distribution patterns of the impact sprinkler under low pressure was previously described ${ }^{[39,40]}$. By raising the pressure to $200 \mathrm{kPa}$, the application rates was higher, and the doughnut-shape pattern was still noticeable for the fixed water dispersion devices tested. For instance, application rates from type $A_{1}$ increased to a maximum of $13.2 \mathrm{~mm} / \mathrm{h}$ at a distance of $8 \mathrm{~m}$ from the sprinkler, and decreased to a minimum of $7.2 \mathrm{~mm} / \mathrm{h}$ under a pressure of $200 \mathrm{kPa}$ (Figure 9a). A possible reason is that type $A_{1}$ had a smaller depth in the jet, and the interruption was inadequate. A poor water distribution pattern is known to waste water and reduce the quality of sprinkler irrigation $^{[21]}$. Type $C_{1}$ gave a maximum application rate of 13.2 $\mathrm{mm} / \mathrm{h}$ at a distance of $4 \mathrm{~m}$ from the sprinkler, and decreased gradually to $3.2 \mathrm{~mm} / \mathrm{h}$ under a pressure of $200 \mathrm{kPa}$ (Figure 9c). The $C V$ from type $\mathrm{C}_{1}$ was $8.1 \%$, while $\mathrm{C}_{2}$ had a least value of $2.8 \%$, which was significantly different $(p>0.05)$ compared with that under a pressure $300 \mathrm{kPa}$. Meanwhile, application rates from type $\mathrm{C}_{2}$ was improved near the sprinkler with the highest value of $13.2 \mathrm{~mm} / \mathrm{h}$ at a distance of $\mathrm{m}$ from the sprinkler, which gradually decreased to $7.2 \mathrm{~mm} / \mathrm{h}$ under a pressure of $200 \mathrm{kPa}$ (Figure 9f). In the case of $\mathrm{C}_{2}$, the $C V$ was $6.1 \%$ with non-significant difference $(p>0.05)$ compared with that under $300 \mathrm{kPa}$. It can be seen that type $\mathrm{C}_{2}$ improved the application rates near and middle range of the sprinkler, while the large sprinkler range was fairly maintained under a pressure of $200 \mathrm{kPa}$. The ideal sprinkler for a large field application is one which uses a water dispersion device to maximize or maintain the range for a given pressure, while avoiding a doughnut-shaped pattern ${ }^{[25]}$. With an increase in pressure, the application rates were much higher near the sprinkler, particularly in the case of type $\mathrm{C}_{1}$ (Figure 9c). Such high application rates can create surface sealing and runoff to carry surface soil away, particularly on light soils ${ }^{[40,41]}$. The jet breaks up sufficiently under such conditions, and the use of the water dispersion devices appears to have facilitated the breakup, resulting in more water applied in the area that very close to the sprinkler. This finding emphasizes on the fact that dispersion devices are only useful in improving water distribution under low pressure conditions.

The differing application rates was attributed to the shape and depth of the fixed water dispersion device in the jet flow. Since the application rates from $\mathrm{C}_{2}$ under $200 \mathrm{kPa}$ were not statistically different from that under $300 \mathrm{kPa}$, it means that type $\mathrm{C}_{2}$ can be selected for further optimization to improve the water distribution and maintain a large sprinkler range.

\subsection{Combined $C U \mathrm{~s}$}

The combined $C U$ s was determined from four sprinklers, which were overlapped in a square layout for the lateral radius $(R)$ times of 1, 1.1, 1.2 1.3, 1.4, 1.5, 1.6, 1.7, 1.81 .9 and 2. As can be seen from Table 3, when the sprinkler was run without a dispersion device, the combined $C U$ s values increased from $30.23 \%$ until it reached its maximum of $68.62 \%$ at $1.7 R$, and then decreased to $66.34 \%$ with an average of $55.44 \%$. Generally, as the spacing was increased, the combined $C U$ s from the dispersion devices first increased to a maximum, and subsequently decreased to a minimum. For example, the range of the combined $C U$ s from type $\mathrm{C}_{1}$ was; $52.22 \%$ at $R$ to $77.23 \%$ at $1.5 R(200 \mathrm{kPa})$, and $60.12 \%$ at $R$ to $84.35 \%$ at $1.7 R(300 \mathrm{kPa})$. The uniformity increased with spacing from $R$ to $1.6 R$ from $52.22 \%$ to $77.23 \%$ with an average of $67.37 \%$. When the distance continued to increase, the uniformity decreased with spacing. From $1.6 R$ to $2 R$, the uniformity ranged from $75.89 \%$ to $55.14 \%$ with an average of $73.06 \%$. Similarly, the combined $C U$ s from type $\mathrm{C}_{2}$ was: $60.08 \%$ at $R$ to $86.67 \%$ at $1.7 R(200 \mathrm{kPa})$, and $63.89 \%$ at $R$ to $88.97 \%$ at $1.7 R(300 \mathrm{kPa})$ The uniformity increased with spacing from $R$ to $1.7 R$, and ranged from $60.08 \%$ to $86.67 \%$ with an average of $75.50 \%$. Starting from this point, the uniformity decreased with spacing from $1.8 R$ to $2 R$ spacing, and the combined $C U$ s ranged from $86.23 \%$ to $77.78 \%$ with an average of $78.79 \%$. Type $\mathrm{C}_{1}$ had a higher $C V$ of $10.4 \%$, while $\mathrm{C}_{2}$ obtained a value of $6.2 \%$ under a pressure of $200 \mathrm{kPa}$ For $\mathrm{C}_{1}$, a significant difference $(p<0.05)$ was found between the $C V$ s of 200 and $300 \mathrm{kPa}$. Simalarly, the $C V \mathrm{~s}$ for type $\mathrm{C}_{1}$ and $\mathrm{C}_{2}$ were $7.3 \%$ and $4.8 \%$, respectively. For type $C_{2}$, a non-significant difference $(p>0.05)$ was found between the CVs under a pressure of 200 and $300 \mathrm{kPa}$. A satisfactory uniformity should be $85 \%$ or more ${ }^{[42]}$. Uniformity values under low and moderate wind speed conditions range from $80 \%$ to $90 \%{ }^{[43]}$. In this study, it appears that the sprinkler with type $\mathrm{C}_{2}$ gives a higher combined $C U$ s for the sprinkler spacing. 


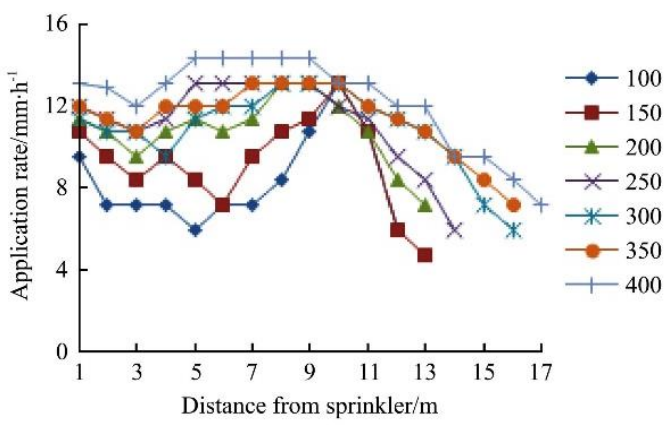

a. $\mathrm{A}_{1}$

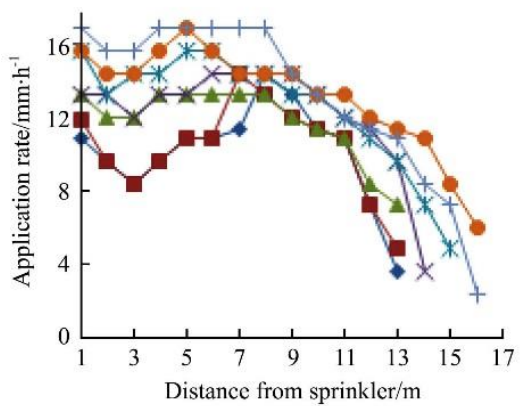

c. $\mathrm{C}_{1}$

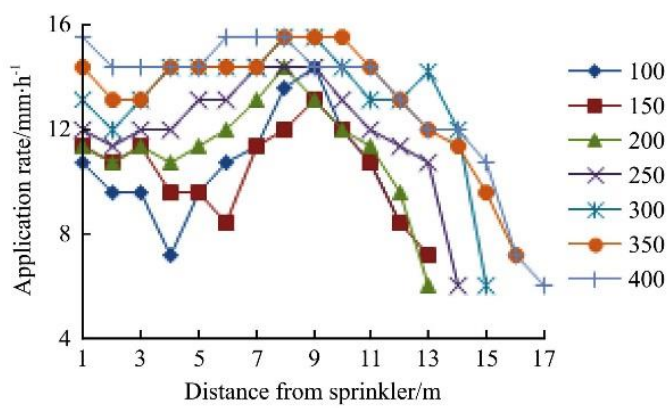

e. $\mathrm{B}_{2}$

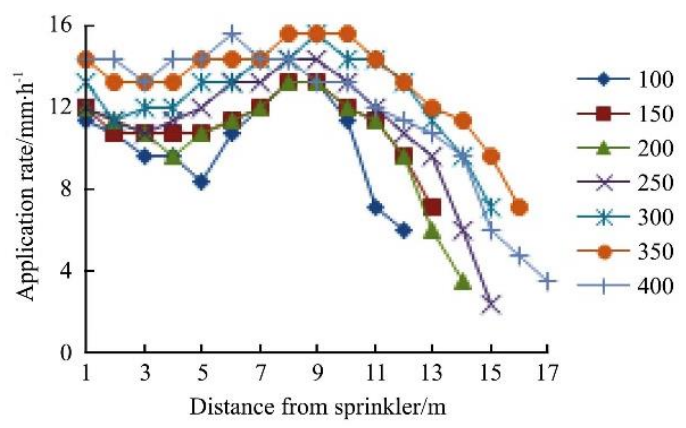

b. $\mathrm{B}_{1}$

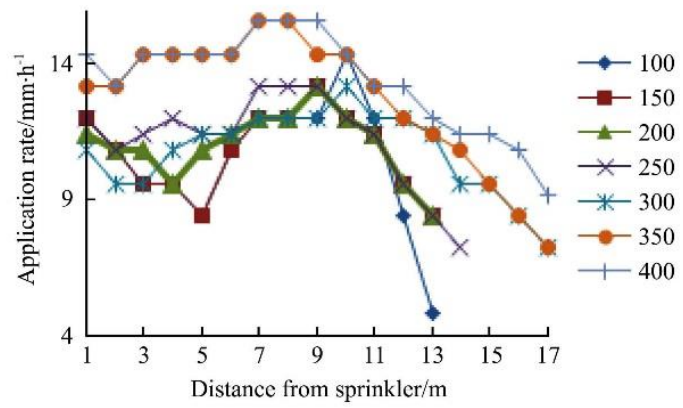

d. $\mathrm{A}_{2}$

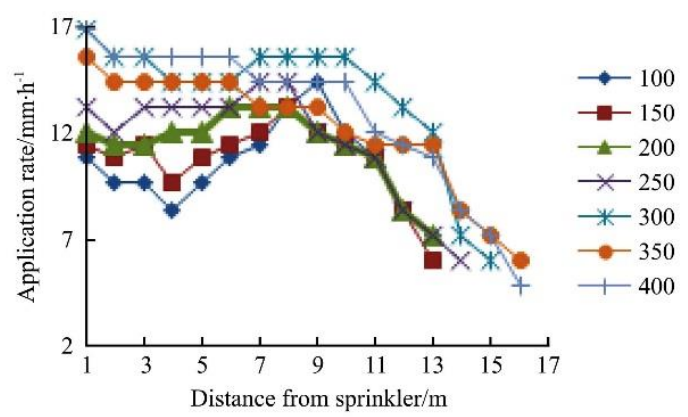

f. $\mathrm{C}_{2}$

Figure 9 Water distribution profiles for the fixed dispersion devices

Table 3 Combined $C U$ s for different types of fixed devices and spacing

\begin{tabular}{|c|c|c|c|c|c|c|c|c|c|c|c|c|}
\hline \multirow{2}{*}{ Type } & \multirow{2}{*}{ Pressure/kPa } & \multicolumn{11}{|c|}{ Spacing along main axis ( $\times$ radius $)$} \\
\hline & & $R$ & $1.1 R$ & $1.2 R$ & $1.3 R$ & $1.4 R$ & $1.5 R$ & $1.6 R$ & $1.7 R$ & $1.8 R$ & $1.9 R$ & $2 R$ \\
\hline \multirow{2}{*}{$\mathrm{A}_{1}$} & 200 & 44.56 & 56.26 & 62.56 & 68.78 & 70.47 & 71.56 & 65.89 & 62.89 & 56.26 & 55.23 & 52.45 \\
\hline & 300 & 50.12 & 58.45 & 63.31 & 70.77 & 73.25 & 76.67 & 73.56 & 70.23 & 65.55 & 60.56 & 58.88 \\
\hline \multirow{2}{*}{$\mathrm{B}_{1}$} & 200 & 43.22 & 50.86 & 58.88 & 64.77 & 70.12 & 75.56 & 74.55 & 71.11 & 67.55 & 60.88 & 52.26 \\
\hline & 300 & 55.56 & 65.25 & 72.28 & 76.87 & 79.91 & 82.23 & 83.37 & 83.33 & 76.66 & 70.98 & 60.88 \\
\hline \multirow{2}{*}{$\mathrm{C}_{1}$} & 200 & 52.22 & 60.34 & 66.25 & 72.56 & 75.66 & 77.23 & 75.89 & 72.56 & 68.56 & 67.23 & 55.14 \\
\hline & 300 & 60.12 & 68.23 & 72.56 & 76.25 & 79.78 & 81.46 & 82.45 & 84.35 & 78.23 & 72.56 & 65.88 \\
\hline \multirow{2}{*}{$\mathrm{A}_{2}$} & 200 & 46.44 & 58.12 & 65.24 & 68.81 & 70.77 & 71.22 & 73.32 & 72.12 & 63.33 & 56.15 & 50.27 \\
\hline & 300 & 49.16 & 60.14 & 68.44 & 70.25 & 73.33 & 75.77 & 76.75 & 78.11 & 66.66 & 60.23 & 57.67 \\
\hline \multirow{2}{*}{$\mathrm{B}_{2}$} & 200 & 50.56 & 58.23 & 65.66 & 70.08 & 73.33 & 75.23 & 78.88 & 76.32 & 73.13 & 63.33 & 52.24 \\
\hline & 300 & 56.67 & 62.33 & 70.27 & 74.58 & 78.87 & 80.22 & 81.47 & 80.33 & 78.81 & 73.33 & 64.44 \\
\hline \multirow{2}{*}{$\mathrm{C}_{2}$} & 200 & 60.08 & 67.77 & 72.28 & 76.67 & 78.03 & 80.25 & 82.26 & 86.67 & 82.23 & 80.77 & 73.38 \\
\hline & 300 & 63.89 & 70.88 & 76.22 & 79.95 & 82.26 & 84.44 & 86.68 & 88.97 & 86.23 & 82.43 & 77.78 \\
\hline \multirow{2}{*}{$\mathrm{N}_{\mathrm{D}}$} & 200 & 30.23 & 37.81 & 40.3 & 46.6 & 50.6 & 58.8 & 61.1 & 68.2 & 67.4 & 67.1 & 66.34 \\
\hline & 300 & 44.61 & 48.23 & 50.61 & 55.4 & 60.82 & 66.25 & 68.78 & 70.23 & 72.12 & 67.2 & 66.21 \\
\hline
\end{tabular}

A comparison of combined $C U$ s from the fixed water dispersion devices revealed a large differences and type $\mathrm{C}_{2}$ produced the highest uniformity for a given pressure and spacing. However, the combined $C U$ s under $200 \mathrm{kPa}$ was slightly lower compared with that under $300 \mathrm{kPa}$. It is possible that after interruption with the fixed water dispersion device, the flow became less uniform, leaving more water applied near the sprinkler. This further demonstrate that $\mathrm{C}_{2}$ could be more suitable under low pressure conditions.

\subsection{Droplet size distributions}

Results of droplet size distributions was obtained at the edge of the wetted radius using the LPM. The weighted cumulative 
frequency means the cumulative ratio between the weighted of droplets under specific size and the total weighted of the spray. It increased along the range of the radial direction, and the droplets with the maximum diameter fell at the terminal position. Figure 10 presents the cumulative droplet diameter frequencies as a function of the droplet diameter from different types of dispersion devices under $200 \mathrm{kPa}, 250 \mathrm{kPa}$ and $300 \mathrm{kPa}$. Generally, the droplets had a wide range of diameters, and the smallest droplets occurred at the edge of the sprinkler ranges. The mean droplet diameters from type $\mathrm{C}_{1}$ were between $0-4.0 \mathrm{~mm}$. The droplets under $1 \mathrm{~mm}$ had cumulative frequencies of $84 \%, 91 \%$, and $70 \%$, under $2 \mathrm{~mm}$ of $91 \%, 92 \%$, and $81 \%$, under $3 \mathrm{~mm}$ of $96 \%, 94 \%$, and $92 \%$ at pressures of $200 \mathrm{kPa}, 250 \mathrm{kPa}$, and $300 \mathrm{kPa}$, respectively (Figure 10c). Similar trends of droplet diameters were observed from dispersion devices with a pointed tip, but at a given distance from the sprinkler, the droplet diameters were larger compared with the dispersion device with a flat tip. This was possibly because the sprinkler range was larger for the dispersion device with a pointed tip. In Figure 10f, the mean droplet diameters from type $\mathrm{C}_{2}$ was between $0-3.8 \mathrm{~mm}$. The droplets under $1 \mathrm{~mm}$ had cumulative frequencies of $77 \%, 80 \%$, and $82 \%$, under $2 \mathrm{~mm}$ of $84 \%, 92 \%$, and $90 \%$, under $3 \mathrm{~mm}$ of $90 \%, 95 \%$, and $96 \%$ at pressures of $200 \mathrm{kPa}, 250 \mathrm{kPa}$, and $300 \mathrm{kPa}$, respectively (Figure 10f). However, the study revealed marginal differences in droplet diameters, particularly between $250 \mathrm{kPa}$ and $300 \mathrm{kPa}$. A possible reason was that the jet flow breaks up into smaller droplets, which settled near the sprinkler when the pressure was higher. Smaller droplets usually concentrate close to the sprinkler with slight differences in the droplet sizes when the pressure was increased ${ }^{[35]}$. Under such condition, the influence of the fixed dispersion device decreases due to inadequate interruption with the jet flow.

The comparison of droplet size distribution from the different types of the fixed water dispersion devices reveals that types $A_{1}$ (a), $B_{1}$ (b), $C_{1}$ (c), $A_{2}$ (d), $B_{2}$ (e), and $C_{2}$ (f) were similar. This result was expected because they were operated with the same type of impact sprinkler. Amongst the six dispersion devices studied, $\mathrm{A}_{2}$ had the narrowest droplet size of $3.5 \mathrm{~mm}$, and type $\mathrm{C}_{2}$ had the widest droplet size range with a maximum value of $4.0 \mathrm{~mm}$. A summary of droplet sizes for $10 \%, 50 \%$, and $90 \%$ from different types of fixed water dispersion devices is provided in Table 4.

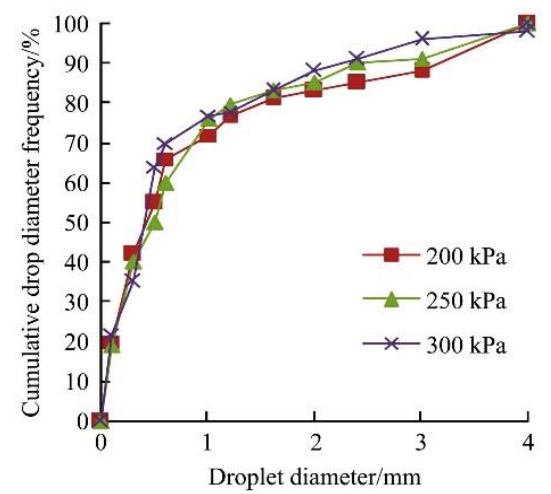

a. $\mathrm{A}_{1}$

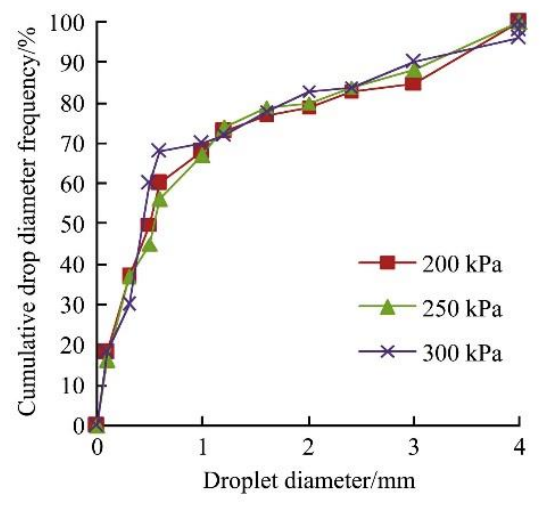

d. $\mathrm{A}_{2}$
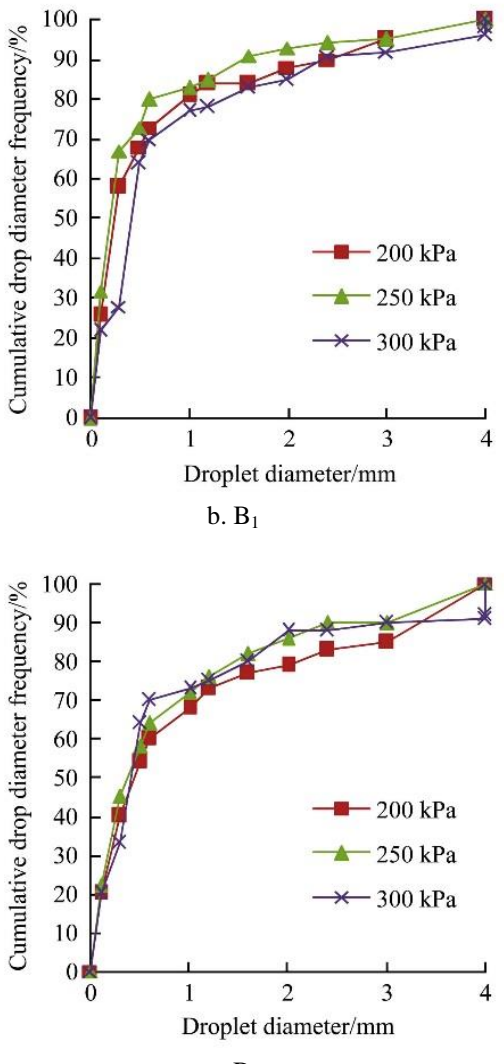

e. $\mathrm{B}_{2}$

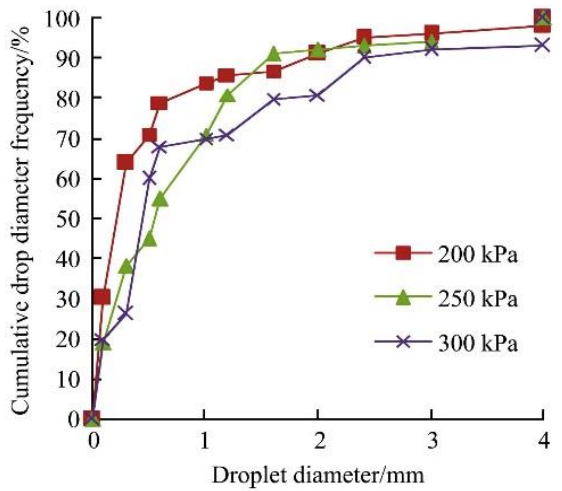

c. $\mathrm{C}_{1}$

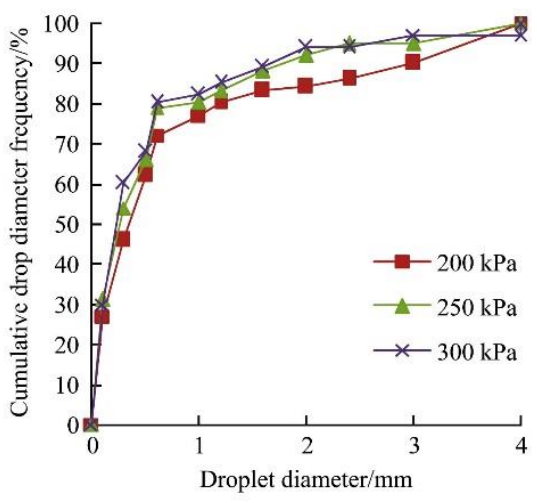

f. $\mathrm{C}_{2}$

Figure 10 Droplet size distributions for the fixed water dispersion devices

Table 4 Droplet sizes for $10 \%, 50 \%$, and $90 \%\left(d_{10}, d_{50}\right.$, and $d_{90}$, respectively $)$ for the fixed dispersion devices

\begin{tabular}{|c|c|c|c|c|c|c|c|c|c|}
\hline \multirow{2}{*}{$\begin{array}{c}\text { Type } \\
P / \mathrm{kPa}\end{array}$} & \multicolumn{3}{|c|}{$d_{10} / \mathrm{mm}$} & \multicolumn{3}{|c|}{$d_{50} / \mathrm{mm}$} & \multicolumn{3}{|c|}{$d_{90} / \mathrm{mm}$} \\
\hline & 200 & 250 & 300 & 200 & 250 & 300 & 200 & 250 & 300 \\
\hline$A_{1}$ & 0.07 & 0.08 & 0.07 & 0.51 & 0.35 & 0.30 & 1.53 & 1.40 & 1.50 \\
\hline $\mathrm{B}_{1}$ & 0.06 & 0.07 & 0.05 & 0.48 & 0.31 & 0.28 & 0.49 & 1.37 & 1.45 \\
\hline $\mathrm{C}_{1}$ & 0.04 & 0.04 & 0.04 & 0.44 & 0.26 & 0.25 & 0.43 & 1.32 & 1.44 \\
\hline $\mathrm{A}_{2}$ & 0.07 & 0.08 & 0.07 & 0.51 & 0.35 & 0.30 & 1.53 & 1.40 & 1.50 \\
\hline $\mathrm{B}_{2}$ & 0.06 & 0.07 & 0.05 & 0.48 & 0.31 & 0.28 & 0.49 & 1.37 & 1.45 \\
\hline $\mathrm{C}_{2}$ & 0.04 & 0.04 & 0.04 & 0.44 & 0.26 & 0.25 & 0.43 & 1.32 & 1.44 \\
\hline $\mathrm{N}_{\mathrm{D}}$ & 0.10 & 0.096 & 0.081 & 0.76 & 0.62 & 0.51 & 0.68 & 1.65 & 1.60 \\
\hline
\end{tabular}


Generally, the mean droplet sizes from the dispersion devices were similar at a given distance from the sprinkler. And the finest droplet size was produced from type $\mathrm{C}_{1}$ which is smaller than the increase rate of the minimum droplet size diameter. Evaporation and wind drift increased greatly as droplet size decreased from $0.6 \mathrm{~mm}$ to $0.3 \mathrm{~mm}^{[44]}$. However, because the maximum droplet diameter decreased, the droplet sizes from type $\mathrm{C}_{1}$ were larger than the increase rate of the minimum droplet size diameter. It means that type $\mathrm{C}_{2}$ may be useful to minimize evaporation and wind drift losses, while preventing damage to the soil.

\subsection{Statistical analysis of droplet diameter}

Table 5 presents the statistical parameters of droplet diameters obtained for the different types of the fixed water dispersion devices.

The parameters include the arithmetic mean, standard deviation, coefficient of variation, the volumetric mean diameter, and the median diameter. There was a general decrease in mean droplet diameter of these parameters for the dispersion devices when the pressure was increased.

The standard deviation of droplet diameter from type $\mathrm{C}_{2}$ ranged from $0.41 \mathrm{~mm}$ to $0.59 \mathrm{~mm}$, with a mean value of $0.51 \mathrm{~mm}$; the coefficients in diameters variation ranged from $76 \%$ to $114 \%$, with a mean value of $96 \%$. For $\mathrm{C}_{1}$, the standard deviation in droplet diameters ranged from $0.62 \mathrm{~mm}$ to $0.79 \mathrm{~mm}$, with a mean value of $0.72 \mathrm{~mm}$, while the coefficients in diameter variation ranged from $92 \%$ to $134 \%$, with a mean value of $107 \%$.

Table 5 Statistical parameters of droplet diameters for different types of fixed water dispersion devices

\begin{tabular}{|c|c|c|c|c|c|c|c|c|c|c|c|c|c|c|c|}
\hline \multirow{2}{*}{$\begin{array}{c}\text { Type } \\
P / \mathrm{kPa}\end{array}$} & \multicolumn{3}{|c|}{$d_{i} / \mathrm{mm}$} & \multicolumn{3}{|c|}{$d_{V} / \mathrm{mm}$} & \multicolumn{3}{|c|}{$d_{50} / \mathrm{mm}$} & \multicolumn{3}{|c|}{$S D_{D} / \mathrm{mm}$} & \multicolumn{3}{|c|}{$C V_{D} / \%$} \\
\hline & 200 & 250 & 300 & 200 & 250 & 300 & 200 & 250 & 300 & 200 & 250 & 300 & 200 & 250 & 300 \\
\hline $\mathrm{A}_{1}$ & 0.82 & 0.73 & 0.66 & 2.6 & 2.22 & 2.20 & 0.22 & 0.21 & 0.22 & 0.85 & 0.66 & 0.73 & 108 & 90 & 111 \\
\hline $\mathrm{B}_{1}$ & 0.88 & 0.77 & 0.70 & 2.78 & 7.73 & 2.14 & 0.36 & 0.22 & 0.21 & 1.01 & 0.98 & 0.93 & 111 & 129 & 132 \\
\hline $\mathrm{C}_{1}$ & 0.76 & 0.77 & 0.73 & 2.85 & 2.35 & 2.20 & 0.42 & 0.30 & 0.24 & 0.62 & 0.75 & 0.79 & 120 & 92 & 108 \\
\hline $\mathrm{A}_{2}$ & 0.89 & 0.78 & 0.60 & 2.30 & 2.01 & 2.01 & 0.18 & 0.17 & 0.15 & 0.47 & 0.55 & 0.61 & 103 & 101 & 101 \\
\hline $\mathrm{B}_{2}$ & 0.84 & 0.76 & 0.56 & 2.58 & 6.82 & 1.81 & 0.21 & 0.20 & 0.18 & 0.81 & 0.72 & 0.74 & 117 & 91 & 120 \\
\hline $\mathrm{C}_{2}$ & 0.66 & 0.60 & 0.47 & 2.11 & 1.55 & 1.73 & 0.32 & 0.27 & 0.20 & 0.41 & 0.53 & 0.59 & 114 & 76 & 98 \\
\hline $\mathrm{N}_{\mathrm{D}}$ & 0.10 & 0.95 & 0.81 & 3.11 & 3.55 & 3.43 & 0.62 & 0.67 & 0.70 & 0.12 & 0.78 & 0.85 & 128 & 100 & 112 \\
\hline
\end{tabular}

\section{Conclusions}

The study on the influence of water dispersion devices $\left(\mathrm{A}_{1}, \mathrm{~B}_{1}\right.$, $\mathrm{C}_{1}, \mathrm{~A}_{2}, \mathrm{~B}_{2}$, and $\mathrm{C}_{2}$ ) on the hydraulic performance for impact sprinkler lead to the following important conclusions:

(1) The sprinkler with type $C_{2}$ produced a rectangular-shaped water distribution pattern, while the sprinkler range was maintained under a pressure of $200 \mathrm{kPa}$.

(2) The maximum combined $C U$ s was $71.56 \%, 75.56 \%$, $77.23 \%, 73.32 \%, 78.88 \%$ and $86.67 \%$ for $\mathrm{A}_{1}, \mathrm{~B}_{1}, \mathrm{C}_{1}, \mathrm{~A}_{2}, \mathrm{~B}_{2}$, and $\mathrm{C}_{2}$ respectively. $C U$ from type $\mathrm{C}_{2}$ surpassed $80 \%$ when the combined spacing was from $R$ to $2 R$. Differences between $C U \mathrm{~s}$ from the two shapes of the fixed water dispersion devices were quite significant under the same operating condition, indicating the importance of the fixed water dispersion devices.

(3) The mean droplet diameter (arithmetic, volumetric, and median) decreased with increasing pressure, and type $\mathrm{C}_{2}$ gave the best droplet sizes.

Therefore, type $\mathrm{C}_{2}$ can be selected for further optimization to improve the hydraulic performance characteristics for the impact sprinkler under low pressure conditions.

\section{Acknowledgements}

This work was supported by the National Natural Science Foundation of China (51679109), the Natural Science Foundation of Jiangsu Province (BK20170555), the Natural Foundation of the Higher Education Institutions of Jiangsu Province (17KJB470001), Special Scientific Research Fund of Agriculture Public Welfare Profession of China (201503130), Jiangsu Scientific Research and Innovation Program for Graduates in the Universities (KYLX15_1062).

\section{[References]}

[1] Montero J, Tarjuelo J, Carrión P. SIRIAS: A simulation model for sprinkler irrigation. Irrigation Science, 2001; 20(2): 73-84.
[2] Zhang L, Merkley G P, Kasem P. Assessing whole-field sprinkler irrigation application uniformity. Irrigation Science, 2013; 31(2): 87-105.

[3] Yuan S Q, Li H, Wang X K. Status problems trends and suggestions for water-saving irrigation equipment in China. Journal of Drainage and Irrigation Machinery Engineering, 2015; 33(1): 78-92.

[4] Yonts C D, Kranz W L, Martin D L. Water loss from above-canopy and in-canopy sprinklers. NebGuide G1328. University of Nebraska-Lincoln extension, Lincoln, Nebraska, 2007.

[5] Yoder R E, Eisenhauer D E. Irrigation system efficiency. In: Heldman D R \& Moraru C I (Eds). Encyclopedia of agricultural, food, and biological engineering, Second edition, 2010; 879-881.

[6] Darouich H; Cameira M R, Gonçalves J M, Paredes P, Pereira L S Comparing sprinkler and surface irrigation for wheat using multi-criteria analysis: water saving vs. economic returns. Water, 2017; 9(50): 1-9.

[7] Akbar G, Ahmad S; Yasin M, Khan Z, Khan A T. Hydraulic performance of raingun sprinkler irrigation system using low capacity dugwell. Journal of Engineering and Applied Science, 2001; 20(2): 90.

[8] Home and Garden Information Center. Landscape irrigation equipment part 1: Sprinkler and spray heads, Clemson University, USA, 2008.

[9] Keller J, Bliesner R D. Sprinkle and Trickle Irrigation. New York, USA: Van Nostrand Reinhold, 1990; 652.

[10] Joshi D S, Shete D T, Modi P M. Sprinkler performance evaluation with respect to nozzle size, pressure, riser height and grid spacing. Proceedings of the ICID special technical session on the role of advanced technologies in making effective use of scarce water resources 95, Rome, Italy: $1995 ; 2$.

[11] Dukes M D, Perry C. Uniformity testing of variable rate center-pivot control systems. Precision Agriculture, 2006; 7(3): 205-218.

[12] Seginer I, Kantz D, Nir D. The distortion by wind of the distribution patterns of single sprinklers. Agricultural Water Management, 1991; 19(4): 341-359.

[13] Schwankl L, Hanson T B. Managing existing sprinkler irrigation systems reducing runoff from irrigated land. Publication 8215, University of California, Division of Agriculture and Natural Resources, USA, 2007.

[14] Kara T, Ekmekci E, Apan M. Determining the uniformity coefficient and water distribution characteristics of some sprinklers. Pakistan Journal of Biological Sciences, 2008; 11: 214-219.

[15] Tarjuelo J M, Montero J, Carrion P A, Honrubia F T, Calvo M A. Irrigation uniformity with medium size sprinkler. I. Characterization of water distribution in no-wind conditions. Transactions of the ASAE, 1999; 42(3): 665-676. 
[16] Loule M J, Selker S. Sprinkler head maintenance effects on water application uniformity. Journal of Irrigation and Drainage Engineering, 2000; 126: 142-148.

[17] Seginer I, Kantz D, Bernuth R D, Nir D. Indoor measurement of single-radius sprinkler patterns. Transactions of ASAE, 1992; 35(2): 523-533.

[18] Li J S. Sprinkler irrigation. Beijing, China: Scientech Press, 2000.

[19] DeBoer D W, Monnens M J, Kincaid D C. Measurement of sprinkler drop size. Applied Engineering in Agriculture, 2001; 17(1): 11-15.

[20] Clark G A, Srinivas K, Rogers D H. Measured and simulated uniformity of low drift nozzle sprinklers. Transactions of ASAE, 2003; 46(2): 1-18.

[21] Gregory C T, Alarecon J J. Rotary sprinkler nozzle for enhancing close-in water distribution. U.S. Patent No. 7325753B2, 2008.

[22] Zhu X, Yuan S Q, Liu J P. Hydraulic performance of impact sprinkler type $\mathrm{PY}_{1}-15$ at low pressure. Transactions of Chinese Society of Agricultural Machinery, 2011; 41(14): 76-80.

[23] Han W T, Cui L H, Wu P T. Calculation methods for irrigation uniformity with sprinklers spaced in regular triangle. Trans. Chinese Society of Agricultural Machinery, 2013; 44(4): 99-107.

[24] Kincaid D C. Sprinkler pattern radius. Transactions of the ASAE, 1982; 25(6): 1668-1672.

[25] Kincaid D C. Impact sprinkler pattern modification. Transactions of ASAE, 1991; 34(6): 2397-2403.

[26] Fan X K, Wu P T, Zhu L. Low-angled sprinkler with controllable atomization. China Patent No. 2649185Y, 2004.

[27] Li H, Jiang Y, Xu M, Li Y, Chen C. Effect on hydraulic performance of low pressure sprinkler by an intermittent water dispersion device. Transactions of the ASABE, 2016; 59(2): 521-532.

[28] Vories E D, von Bernuth R D, Mickelson R H. Simulating sprinkler performance in wind. Journal of Irrigation and Drainage Engineering, 1987; 113(1): 119-130.

[29] Seginer I, Mir D, von Bernuth R D. Simulation of wind-distorted sprinkler patterns. Journal of Irrigation and Drainage Engineering, 1991; 117(2): 285-305.

[30] Bedaiwy M N A. Mechanical and hydraulic resistance relations in crust-topped soils. Catena, 2008; 72(2): 270-281.

[31] Lehrsch G A, Gallian J J. Oilseed radish effects on soil structure and soil water relations. Journal of Sugar Beet Residue, 2010; 47(1-2): 1-21.

[32] Kincaid D C. Spraydrop kinetic energy from irrigation sprinklers. Transactions of ASAE, 1996; 39(3): 847-853.

[33] American Society of Agricultural and Biological Engineers. ASABE Standards (R2007). S398.1: Procedure for sprinkler testing and performance reporting. St Joseph, Mich., USA, 2007.

[34] Wang C, Cai B. Allotype spout with pressure compensating variable cross-section. China Patent No. 101530833A, 2009.

[35] Zhu X, Yuan S, Liu J, Liu X. Comparison of droplet distributions from fluidic and impact sprinklers. Frontiers of Agricultural Science Engineering, 2015; 2(1): 53-59.

[36] Liu J P, Yuan S Q, Li H. Combination uniformity improvement of impact sprinkler. Transactions of CSAE, 2011; 27(7): 107-111.

[37] Christiansen J E. Irrigation by Sprinkling. California Agricultural Experiment Station, Bulletin 670, 1942.

[38] King B A, Winward T W, Bjorneberg D L. Laser precipitation monitor for measurement of drop size and velocity of moving spray-plate sprinklers. Applied Engineering in Agriculture, 2010; 26(2): 263-271.

[39] Bautista C, Zavala M, Playán E. Kinetic energy in sprinkler irrigation: different sources of drop diameter and velocity. Irrigation Science, 2012; 30(1): 29-41.

[40] Li J, Kawano H. Sprinkler rotation non uniformity and water distribution. Transactions of the ASAE, 1996; 39(6): 9.

[41] Michael A M. Irrigation. Theory and practice. New Delhi, India: Vikas Publishing House. PVT LTD, 1978.

[42] Dwomoh F A, Yuan S, Hong L. Field performance characteristics of fluidic sprinkler. Applied Engineering in Agriculture, 2013; 29(4): 529-536.

[43] Dwomoh F A, Yuan S Q, Li H. Sprinkler rotation and water application rate for the newly designed complete fluidic sprinkler and impact sprinkler Int J Agric \& Biol Eng, 2014; 7(4): 38-46.

[44] Edling R J. Kinetic energy, evaporation and wind drift of droplets from low pressure irrigation nozzles. Transactions of the ASAE, 1985; 28(5): $1543-1550$ 